\title{
The development of an intervention to manage pain in people with late-stage osteoarthritis
}

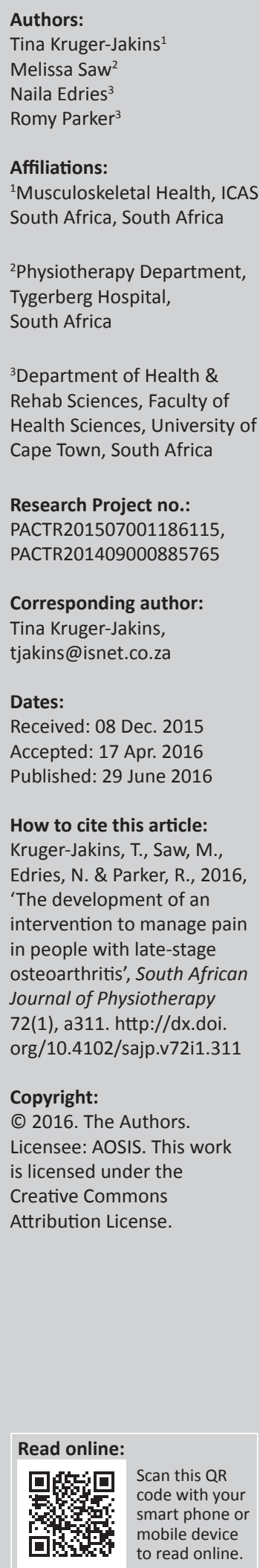

\begin{abstract}
Background: Osteoarthritis (OA) is one of the most common musculoskeletal conditions worldwide, affecting the functional abilities of millions of people. Arthroplasty is recommended as a successful treatment option for late-stage OA. However, in South Africa there are extensive waiting lists for OA-related arthroplasty in government hospitals. This has negative consequences for patients having to cope for long periods of time with chronic pain and its impact. Alternative treatment methods in the form of physiotherapy-led exercise and education programmes focusing on pain, disability, self-efficacy, physical function and health-related quality of life have had good impact in populations elsewhere.
\end{abstract}

Objectives: To develop an exercise and education intervention based on the current literature and by doing a field survey in a South African population.

Results: A combined educational approach, with a strong focus on the physical aspects of exercise in particular, was adopted for the intervention in order to improve function and manage the disability associated with OA.

Conclusion: This paper reports on the process and development of an intervention for use in South Africans with late-stage OA awaiting arthroplasty.

\section{Introduction}

Worldwide, the prevalence of musculoskeletal conditions is high (Brooks 2006; Lidgren 2003; World Health Organization 2003). One of the most common musculoskeletal conditions is osteoarthritis (OA), which is accompanied by a range of symptoms including pain and loss of function. OA is considered one of the most common causes of severe long-term pain and disability (Brooks 2002; Helmick et al. 2008). Disability is associated with lack of function, which in turn has detrimental consequences for the individual's activities of daily living and thereby health-related quality of life (Alviar et al. 2012; Jelsma et al. 2004). In 2003, Woolf and Pfleger reported that the worldwide incidence of OA was on the increase, affecting both men and women, with women being affected at a higher rate than men The trend has continued throughout the last 10 years (Litwic et al. 2013; Zhang \& Jordan 2010).

In South Africa, the prevalence of OA is similarly high (Usenbo et al. 2015). The added complications of low socio-economic demographics, limited access to healthcare, as well as a high prevalence of other chronic conditions, such as HIV straining healthcare resources, makes management of this non-communicable chronic condition challenging (Brooks 2006; Lidgren 2003; World Health Organization 2003). Despite pain being identified as a problem in people living with late-stage $\mathrm{OA}$, the non-pharmacological treatment options such as education, exercise, and surgery to manage the burden of pain in these individuals are limited (Lorig, Ritter \& Plant 2005a).

A growing evidence base indicates that intervention programmes for chronic conditions such as OA need to be bio-psychosocial in nature (Lorig et al. 2005a, 2005b; Swendeman, Ingram \& Rotheram-Bonus 2009). These interventions are proving successful in the management of many different chronic disorders including OA (Hurley et al. 2007a; Lorig et al. 2005a). However, evidence to support the application of bio-psychosocial treatment interventions in South Africa is lacking. A key component of these bio-psychosocial interventions is health education aimed at enabling patients with chronic disorders to achieve behaviour changes advantageous to health through increasing knowledge and self-efficacy (Hurley et al. 2007; Lamb, Toye \& Barker 2008).

Evidence suggests several benefits to combining bio-psychosocial education with exercise (Hurley, Mitchell \& Walsh 2003; Lamb, et al. 2008). The Enabling Self-management and Coping with Arthritic Pain using Exercise (ESCAPE) knee pain programme for knee OA (Hurley et al. 2007) is 
a bio-psychosocial intervention enabling self-management and coping with arthritic knee pain through education and exercise. Such rehabilitation programmes are designed to improve function by integrating exercise, education and selfmanagement strategies to dispel inappropriate health beliefs, alter behaviour and encourage regular physical activity (Hurley et al. 2012; Jessep et al. 2009). The benefits of the ESCAPE programme include improved function, pain, selfefficacy and health beliefs with large effect sizes. The ESCAPE knee pain programme appears to be an effective and sustainable treatment option having been tested in several robust studies in the United Kingdom (Hurley et al. 2012).

Further evidence to support the health and clinical benefits of a bio-psychosocial intervention is provided by the TOAP (Taipei Osteoarthritis Program) (Wu et al. 2011). A programme developed and tested in Taipei city districts. Similar to the ESCAPE knee programme, the TOAP focuses on self-efficacy and behaviour changes enabling selfmanagement. The programme is delivered in small groups and facilitated by a trained physiotherapist. TOAP includes patient education, exercise and participation in discussions aiming to assist people to maintain a healthy lifestyle, seek support, solve problems and make action plans (Wu et al. 2011), elements which resonate throughout the literature and therefore important to consider in the development of an intervention.

There is a strong rationale for developing and implementing bio-psychosocial interventions for patients with OA. Such a multidimensional model of treatment aligns with the International Classification of Function, Disability and Health (ICF) guidelines (Bagraith \& Strong 2013) for including not only the individual but also the surrounding environment combining the whole functional and able individual. In addition to the personal benefits, intervention programmes have been shown to be cost effective, with fewer visits to healthcare facilities (Hurley et al. 2007b, 2012). Furthermore, for people eligible for arthroplasty, there is evidence that biopsychosocial intervention programmes may improve surgical outcomes (Ayers, Franklin \& Ring 2013)

Conclusively, because of the strong evidence available internationally with regards to the benefits and safety of selfmanagement focused interventions for people living with OA, the aim of this study was to develop an intervention to manage pain in people living with OA awaiting arthroplasty in South Africa. The majority of South Africans are dependent on public healthcare, and waiting times for elective surgery in this sector is knowingly much longer than in the private sector, often extending into year-long waiting periods (South African Government 2014).

\section{Method}

In order to develop a feasible evidence-based biopsychosocial intervention to manage pain in people with late-stage OA in South Africa, a three-step approach was adopted. The first step was to draw specific evidence on the management of late-stage OA primarily based on international evidence-based guidelines (Osteoarthritis Research Society International [OARSI] and NICE Guidelines) and their recommendations for the management of OA (McAlindon et al. 2014; O'Mahony \& Oliver 2008). This was followed by conducting a narrative review of intervention programmes already in use in South Africa for various chronic pain conditions in order to identify components appropriate for pain in OA relevant to the population. The search for such intervention programmes was conducted through PubMed and Elton B. Stephens Company (EBSCO) for all publications up to and including 2013 using the following search terms: musculoskeletal conditions, arthritis, osteoarthritis, chronic pain, health related quality of life, disability, function, self-efficacy, South Africa, ICF, epidemiology, intervention programs, self-management programs. In addition, chronic pain management programmes in use at public health institutions were reviewed (Groote Schuur Hospital 2012; Helen Joseph Hospital 2012). Of specific interest were programmes that included both educational and exercise components. Intervention programmes combining both elements show better outcomes than educational programmes alone as they improve functional as well as self-efficacy outcomes (Brady et al. 2003; Jensen et al. 2013). This was followed by the final step of a field search to locate appropriate settings for testing the intervention.

Evidence was drawn from the literature on intervention programmes already in place to guide the development of an intervention programme appropriate for use in South Africans with late-stage OA (Edries, Jelsma \& Maart 2013; Parker, Jelsma \& Stein 2014). The information was categorised according to the intervention components: education, exercise and relaxation. Further categories explored were: setting or site and length of delivery. The field investigation located sites that would be appropriate for running such an intervention and which could be used in a study to investigate the effectiveness of the intervention. The field investigation was conducted through site visits, where geographical location, patient group, safety, accessibility and physiotherapy availability were considered. Sites were considered if they had adequate facilities (a hall or gym space, chairs and were private), were accessible via public transport and provided treatment for patients with late-stage OA. Patients were diagnosed as having late-stage OA radiographically by the orthopaedic consultants at the healthcare facilities, as classified according to the Kellgren and Lawrence plain radiograph classification scale (Kijowski et al. 2006).

\section{Results}

A 6-week, physiotherapist-led exercise and education intervention was designed based on the literature reviewed and considering the South African health-care context within the ICF framework (Brady et al. 2003; Edries et al. 2013; Gatchel et al. 2014; Hurley et al. 2007a; Hurley \& Walsh 2009; Jessep et al. 2009; Parker 2013). While health education is a cornerstone to improving knowledge, self-efficacy and health promotion, it does not necessarily lead to behaviour change 
and an empowered patient (Parker, Jelsma \& Stein 2014). Parker et al. (2014) argue that 'in order for changes in knowledge and belief to translate into behaviour changes, cognitive behavioural approaches with goal setting need to be adopted' (2014:14). Therefore, a combined educational approach, with a strong focus on the physical aspects of exercise in particular was adopted for the intervention in order to improve function and manage the disability associated with OA. The specific information, which was drawn from the literature and used to develop the intervention, will be presented first, followed by the findings from the site inspections (Brady et al. 2003; Edries et al. 2013; Gatchel et al. 2014; Hurley et al. 2007a; Hurley \& Walsh 2009; Jessep et al. 2009; Parker 2013).

\section{Theoretical Model}

The intervention used the principles of social learning and cognitive behavioural theory, such as problem solving and goal setting, which aim to achieve behaviour change and build confidence, as its primary theoretical model (Lorig \& Holman 2003). Instructive health education programmes have shown limited effectiveness in managing function in people with chronic diseases (Von Korff et al. 2005). Therefore, in order for knowledge and beliefs to translate into behaviour changes with positive impact on function and quality of life, cognitive behavioural approaches; primarily through goal setting, need to be adopted.

\section{Educational Content}

Despite education alone not leading to desirable behaviour change, studies have been seen to support the use of education to reduce pain and anxiety in patients awaiting total hip arthroplasty (Von Korff et al. 2005). In order for education to be effective, the components need to be relevant to the management of OA, focusing on self-management in terms of psychological wellbeing, quality of life and selfefficacy (Ottawa Panel 2011).

An example of a commonly used patient education intervention is the Chronic Disease Self-Management Program (CDSMP) (Stanford School of Medicine 2015). The CDPSMP is a workshop given over two-and-a-half hours, once a week, for 6 weeks, in a community setting. Educational topics covered include: (1) techniques to deal with problems such as frustration, fatigue, pain and isolation; (2) appropriate exercise for maintaining and improving strength, flexibility and endurance; (3) appropriate use of medications; (4) communicating effectively with family, friends and health professionals; (5) nutrition; (6) decision making; and (7) how to evaluate new treatments. Each participant in the workshop receives a copy of the companion book, 'Living a Healthy Life with Chronic Conditions' and an audio relaxation CD, 'Relaxation for Mind and Body'. 'Classes are participative, where mutual support and success build the participants' confidence in their ability to manage their health and maintain active and fulfilling lives' (Stanford School of Medicine 2015).
Lorig et al. (2001) found that the CDSMP produced significant improvements in health distress and reductions in ambulatory healthcare for chronic illnesses including unspecified arthritis (Lorig et al. 2001).

The Ottawa Panel (2011) has recently reviewed evidence to develop practice guidelines for patient education programmes in the management of OA (Ottawa Panel 2011). They recommended that a self-management programme should apply social learning theory to empower participants moving them away from the traditional passive informationreceiving role. When interventions contain self-management education based on social learning theory, improvements are recorded in pain, disability and overall health status (Wu et al. 2011). The model of education used is an important aspect to consider thereby avoiding the pitfalls of depending on an individual therapeutic relationship to achieve a treatment effect.

For the development of the intervention for this study, the educational topics were therefore incorporated into a progressive goal-oriented programme allowing the participants to implement self-management skills based on knowledge. Each week focused on a specific topic identified as relevant and useful for patients through the literature review (Table 1). In addition, the educational topics were incorporated into a workbook titled: 'Living with Osteoarthritis' covering in detail the same topics discussed in the weekly sessions. Both the workbook and the educational sessions of the intervention programme aimed at facilitating the development of the core self-management skills of problem solving and decision making. To allow for a transfer of knowledge into action, the handbook included an exercise diary, SMART (specific,

TABLE 1: Topics and content of the 'Living with Osteoarthritis' workbook.

\begin{tabular}{ll}
\hline Topic for the week & Content \\
\hline Week 1: & What is osteoarthritis \\
Osteoarthritis, self-management & Management options \\
and exercise & Exercise dos and don'ts \\
& Types of exercise \\
& Steps to success with exercise \\
& Exercise routines \\
Week 2: & What is pain? \\
Managing common symptoms & Flare-ups of pain and what can I do? \\
& Stiffness and how to manage \\
& Activity limitations because of symptoms \\
& Assistive devices \\
& Pacing \\
& Fatigue \\
& Depression, frustration, isolation \\
Week 3: & What is stress? \\
Stress management & Managing stress \\
& Communication with your family \\
& Sleep routine \\
& Planning ahead \\
Relaxation techniques \\
Week 4: & Two schools of thought: choosing a diet \\
Eating well & The role of food groups \\
& Eating guidelines \\
Continuing as a successful self-manger & Losing weight \\
\hline & Steps to healthier eating \\
Week 5: & Analgesic drugs \\
Medication and disease- & Anti-inflammatories \\
related problem solving & Anti-spasmodic drugs \\
& Epileptic and anti-depressants \\
& The analgesic ladder \\
& Making informed decisions \\
& Action planning for the future \\
&
\end{tabular}

Source: http://open.uct.ac.za/handle/11427/12697 
measurable, attainable, realistic and timed) goal setting sheets and problem-solving tasks (Parker et al. 2014).

The workbook was divided into six chapters, encouraging participants to work through the subjects at regular intervals simultaneously with the subjects taught in contact sessions. As self-management, in particular with exercise components, has been found to have an overall positive reduction of pain, the workbook also included information on exercise, exercise programmes and planning of such (Ottawa Panel 2011).

\section{Skills Development}

A participation agreement was designed to be signed by all participants. The agreement aimed at facilitating open discussion while maintaining respect and confidentiality among the group members. The agreement also aimed at encouraging commitment to the programme and facilitating active participation in skills development. Further skills development included the workbook section of 'activity planning'. Here the participants were taught the skills of developing action plans in accordance with content learned at the workshop. This was designed to develop the skill of progressively advancing goals set on a weekly basis.

\section{Exercise Content}

OARSI and the National Institute for Health and Care Excellence (NICE) guidelines state that local muscle strengthening exercises and general aerobic fitness should be part of core treatments for people with OA, irrespective of age, co-morbidity, pain severity or disability (McAlindon et al. 2014; O'Mahony \& Oliver 2008). These exercise recommendations are based on evidence with large effect sizes. Positive effects in terms of pain reduction and improvements in function have been reported after a combined approach of aerobic and strengthening exercise (Escalante et al. 2010; Hiyama et al. 2012; van Tulder et al. 2000). One such programme was the previously mentioned ESCAPE knee pain programme, which combined strengthening and aerobic exercises in a progressive manner.

The exercise components for the intervention designed for theSouth African population combined aerobic, strengthening and flexibility activities and was largely based on the ESCAPE knee pain programme by Hurley et al. (2007a, 2009) (Table 2). The content of the programme falls within the parameters of the OARSI and NICE guidelines (McAlindon et al. 2014; O'Mahony \& Oliver 2008). Furthermore, the ESCAPE knee programme is similar to other evidence-based exercise programmes that have been used in South African populations with chronic pain (Parker et al. 2009, 2014). The exercise programme is designed to be applied in a group setting and is easy to modify for the individual participant depending on their current state of symptoms and abilities. Exercises were chosen on a basis of safety, simplicity (no equipment needed) and ability to adapt to progression in aerobic fitness and muscle strength. The exercise programme was designed to start at 20 minutes in length during the first week with the duration increasing by $10 \%$ each week. Instructions for the exercises included in the workbook indicated that all aerobic exercises should be carried out at $60 \%$ of maximum heart rate based on the Borg scale of exertion using the descriptive term 'somewhat hard' (Borg 1998). Flexibility and strengthening exercises focused on muscle groups relevant to the participants with diagnoses of OA of the lower limbs.

\section{Relaxation Content}

Late-stage OA predominantly presents as chronic pain with several psychosocial factors influenced by/influencing the pain experience (Gatchel et al. 2014). Therefore, it is appropriate to consider including other non-pharmacological management approaches in addition to education and exercise. As discussed, the educational component is based on a cognitive behavioural approach, a model shown to have a positive effect in the treatment of people with chronic pain (Gatchel et al. 2014). Cognitive behavioural interventions promote significant improvements in multiple psychosocial dimensions of chronic pain (e.g. coping, pain behaviour and social functioning) (Lunde \& Nordhus 2009) and usually include a component of relaxation or mindfulness training (Gatchel \& Rollings 2008; McCracken \& Turk 2002).

Diezeman (2011) reports that progressive muscle relaxation (which entails a short contraction of a muscle group followed by complete relaxation of the same group) is the

TABLE 2: Exercises included in the intervention.

\begin{tabular}{|c|c|c|c|}
\hline Type of exercise & Aim & Activities & Progression \\
\hline Walking & $\begin{array}{l}\text { Warm up } \\
\text { Improve Cardiovascular fitness }\end{array}$ & Walking on the spot & $\begin{array}{l}\text { Increase speed and reps, incorporate arm swings and } \\
\text { boxing. Take bigger steps. Lift knees higher }\end{array}$ \\
\hline Quads and hamstring strength & Isotonic lower limb strength & $\begin{array}{l}\text { Knee extension exercises. Kicking backwards } \\
\text { towards buttocks }\end{array}$ & Increase speed and reps \\
\hline Upper limb movements & $\begin{array}{l}\text { Range of movement improvement for } \\
\text { upper limbs and trunk }\end{array}$ & $\begin{array}{l}\text { Reaching up and sideways, while walking on the } \\
\text { spot }\end{array}$ & $\begin{array}{l}\text { Increase speed and coordination with different } \\
\text { movements }\end{array}$ \\
\hline Standing on one leg & Balance and coordination & Single lag stance, support wall & Increase reps, stand on matt (soft), no support wall \\
\hline Sit to stand & Strength, control, function & With arms folded sit to stand from chair or bench & Decrease height, increase time \\
\hline Floor squats & Strength and control & $\begin{array}{l}\text { Standing near support, squatting as far as } \\
\text { possible }\end{array}$ & $\begin{array}{l}\text { Increase time. Exercise only introduced in advanced } \\
\text { stages }\end{array}$ \\
\hline Stretches & Range of motion and flexibility & $\begin{array}{l}\text { Stretches of major upper limb and lower limb } \\
\text { muscle groups }\end{array}$ & Not applicable \\
\hline Interactive activities & $\begin{array}{l}\text { Social, fun, CV, balance, concentration, } \\
\text { coordination }\end{array}$ & $\begin{array}{l}\text { Large gym-ball bouncing between participants, } \\
\text { stepping and saying each other's names, etc. }\end{array}$ & $\begin{array}{l}\text { Use smaller ball and throw to each other, add more } \\
\text { difficult games, stand in line and pass ball backwards }\end{array}$ \\
\hline
\end{tabular}

Source: Authors' own work 
most commonly used and best studied relaxation method used by physiotherapists. The technique leads to distraction from pain, allowing internal focus of control and improvement of self-efficacy (Diezeman 2011). Targets of relaxation training are 'Improvement of body awareness and stress management, shielding from sensory stimuli as well as serving as a sleeping aid' (Diezeman 2011). This method has good compliance with patients because it is easy to learn (Diezeman 2011).

While the above evidence for relaxation training is mainly based on populations with chronic low back pain, headaches and fibromyalgia, recent literature highlighting the central nervous system changes present in late-stage OA supports the application of the approaches in this population (Lluch et al. 2014). The relaxation component of the intervention programme was designed based on the literature available (Diezeman 2011; Gatchel \& Rollings 2008; Lluch et al. 2014; McCracken \& Turk 2002). The relaxation component includes appropriate imagined visualisations/relaxation journeys combined with contract/release of major muscle groups. The relaxation component was designed to be conducted with the participants sitting or lying down on comfortable mats with pillows for support at every session. The environment was quiet and shielded from outside noise and distraction. In addition to the relaxation session conducted at the weekly workshop, a CD was recorded for participants to use in their home environments.

\section{The Sites}

Social isolation is a known problem for patients with chronic illnesses (Chan \& Chan 2011) and there are positives to be derived from group treatments, in terms of social interaction. The intervention was therefore designed for a group setting of a maximum of 12 participants. This number of participants allows for individual attention, as well as the group benefits of social learning, that is, motivation from seeing other participants achieving goals benefitting their health and vicarious learning (Chan \& Chan). Further to this, the sites selected for delivery of the intervention needed to be familiar to participants, accessible and safe. Sites at public health institutions were identified, which had appropriate space, privacy and transport availability.

\section{Physiotherapist-led Facilitation}

One of the biggest obstacles in modern healthcare practice is adherence to guidelines and despite evidence-founded recommendations, their practice is often not followed (Walsh \& Hurley 2009). However, the OARSI guidelines do recommend exercises be prescribed by an appropriate specialist (McAlindon et al. 2014). Reliance on general practitioners to prescribe exercises may be inappropriate both from a time and skill perspective, whereas physiotherapists, who are skilled in assessment, exercise prescription, biomechanical dysfunction and behavioural interventions (pacing and action planning), are ideally placed to provide this specialist service (McAlindon et al. 2014; O’Mahony \& Oliver 2008).

\section{Length of Delivery}

CDSMPs commonly range from 6-10 weeks in length (Foster et al. 2007; Marks, Allegrante \& Lorig 2005; Parker et al. 2014). Interventions lasting for longer periods of time have greater dropout rates, which may negatively affect outcome. The Stanford Education Research Centre has tested several chronic disease management programmes and has found that an appropriate length of delivery to be between 6 and 7 weeks. This allows for enough time to accommodate behaviour changes, but at the same time is not regarded as excessively long by participants (Lorig et al. 2005b; Lorig \& Holman 2003). Therefore, for the intervention designed for a South African population with late-stage OA where challenges are faced in terms of adherence, a 6-week period was selected.

\section{Conclusion}

This paper illustrates the process followed to develop an evidence-based 6-week physiotherapist-led exercise and intervention for South African patients with late-stage OA of the hip or knee. The 'Living with Osteoarthritis' biopsychosocial intervention was specifically developed for the management of pain, function, disability and health-related quality of life in patients waiting for arthroplasty of the hip or knee because of OA. The workbook can be accessed at: https:/ / open.uct.ac.za/handle/11427/12697. The effectiveness of the intervention has been tested in a randomised trial, the results of which are reported elsewhere.

\section{Acknowledgements}

Funding for this study was received from South African Society of Physiotherapy, Margaret Roper Scholarship and UCT PG funding. The authors thank the staff, research assistants, translators and patients who made research possible at Tygerberg and Helen Joseph Hospitals.

\section{Competing interests}

The authors declare that they have no financial or personal relationships which may have inappropriately influenced them in writing this article.

\section{Authors' contributions}

R.P. was the project leader. T.K-J. and M.S. identified the need for the development of the intervention and made substantial contributions to the conception and design of the intervention; T.K-J. was primary investigator and responsible for the site investigations at the Helen Joseph Hospital in Gauteng; was involved in literature review and analysis and primarily drafted the manuscript. M.S. made substantial contributions to design of the intervention; was the primary investigator and responsible for the site investigations at Tygerberg Hospital Cape Town; was involved in literature analysis and assisted in critically revising the manuscript. N.E. made contributions to the design of the intervention, was the cosupervisor of the study in which the intervention was tested 
and assisted in critically revising the manuscript. R.P. made substantial contributions to the conception and design intervention, was the primary supervisor of the study, was involved in literature analysis and assisted in critically revising the manuscript.

All authors read and gave final approval of the version to be published and agree to be accountable for all aspects of the work in ensuring that questions related to the accuracy or integrity of any part of the work are appropriately investigated and resolved.

\section{References}

Alviar, M.J., Oliver, J., Pallant, J.F., Brand, C., de Steiger, R., Pirpiris, M., et al., 2012, 'Can the ICF osteoarthritis core set represent a future clinical tool in measuring functioning in persons with osteoarthritis undergoing hip and knee joint replacement?', Journal of Rehabilitation Medicine: Official Journal Of The UEMS European Board Of Physical And Rehabilitation Medicine 44(11), 955-961, viewed 7 December 2015, from http://www.ncbi.nlm.nih.gov/pubmed/22948262

Ayers, D.C., Franklin, P.D. \& Ring, D.C., 2013, 'The role of emotional health in functional outcomes after orthopaedic surgery: Extending the biopsychosocial model to orthopaedics', The Journal of Bone \& Joint Surgery 95(21), e165, viewed 1 November 2015, from http://dx.doi.org/10.2106/JBJS.L.00799

Bagraith, K. \& Strong, J., 2013, 'The International Classification of Functioning Disability and Health (ICF) can be used to describe multidisciplinary clinical assessments of people with chronic musculoskeletal conditions', Clinical Rheumatology 32(3), 383-389, viewed 7 December 2015, from http://www.ncbi. nlm.nih.gov/pubmed/23318704

Borg, G., 1998, Borg's Perceived exertion and pain scales, 1st edn., Human Kinetics, Champaigne, I.L.

Brady, T.J., Kruger, J., Helmick, C.G., Callahan, L.F. \& Boutaugh, M.L., 2003, 'Intervention programs for arthritis and other rheumatic diseases', Health Education \& Behavior programs for arthritis and other rheumatic diseases', Health Education \& Behavior
$30(1), 44-63$, viewed 7 December 2015, from http://www.ncbi.nlm.nih.gov/ $30(1), 44-63$, view
pubmed/12564667

Brooks, P.M., 2002, 'Impact of osteoarthritis on individuals and society: How much disability? Social consequences and health economic implications', Current Opinion Rheumatology 14(5), viewed 7 December 2015, from http://espace. Opinion Rheumatology 14(5), viewe
library.uq.edu.au/view/UQ:64297

Brooks, P.M., 2006, 'The burden of musculoskeletal disease - A global perspective' Clinical Rheumatology 25(6), 778-781, viewed 7 December 2015, from https:// www.readbyqxmd.com/read/16609823/the-burden-of-musculoskeletal-diseasea-global-perspective

Chan, K.K.W. \& Chan, L.W.Y., 2011, 'A qualitative study on patients with knee osteoarthritis to evaluate the influence of different pain patterns on patients' quality of life and to find out patients' interpretation and coping strategies for the disease', Rheumatology Reports 3(1), 9-15, viewed 7 December 2015, from disease', Rheumatology Reports 3(1),
http://dx.doi.org/10.4081/rr.2011.e3

Diezeman, A., 2011, 'Relaxation techniques for chronic pain', Schmerz (Berlin, Germany) 25(4), 445-453, viewed 7 December, 2015, from http://www.ncbi.nlm. nih.gov/pubmed/21818724

Edries, N., Jelsma, J. \& Maart, S., 2013, 'The impact of an employee wellness programme in clothing/textile manufacturing companies: a randomised controlled trial', BMC Public Health, 13(1), 1-9, viewed 7 December, 2015, from http://www.ncbi.nlm.nih.gov/pmc/articles/PMC3574831

Escalante, Y., Saavedra, J.M., Garcia-Hermoso, M., Silva, A.J. \& Barbosa, T.M., 2010 'Physical exercise and reduction of pain in adults with lower limb osteoarthritis: A systematic review', Journal of Back and Musculoskeletal Rehabilitation 23(4), 175-186, viewed 7 December 2015, from http://www.ncbi.nlm.nih.gov/ pubmed/21079296

Foster, G., Taylor, S.J., Eldridge, S.E., Ramsay, J. \& Griffiths, C.J., 2007, 'Self-management education programmes by lay leaders for people with chronic conditions', Cochrane Database of Systematic Reviews 17(4), viewed 7 December 2015, from http://europepmc.org/abstract/MED/21818724

Gatchel, R.J., McGeary, D.D., McGeary, C.A. \& Lippe, B., 2014, 'Interdisciplinary chronic pain management: Past, present, and future', American Psychologist 69(2), 119-130, viewed 7 December 2015, from http://www.ncbi.nlm.nih.gov/ pubmed/24547798

Gatchel, R.J. \& Rollings, K.H., 2008, 'Evidence-informed management of chronic low back pain with cognitive behavioural therapy', The Spine Journal: Official Journal of The North American Spine Society 8(1), 40-44, viewed 7 December 2015, from http://europepmc.org/abstract/MED/18164452

Groote Schuur Hospital/University of Cape Town, 2012, 'Chronic Pain Management Programme, session 1-6', Physiotherapy Outpatient Department, observed from February to March 2012

Helen Joseph Hospital, 2012, 'Chronic Pain Patient Group, session 1-6', Department of Outpatient Physiotherapy/Department of Anaesthesiology, observed from April to May 2012.

Helmick, C.G., Felson, D.T., Lawrence, R.C., Gabriel, S., Hirsch, R., Kwoh, C.K., et al 2008 , 'Estimates of the prevalence of arthritis and other rheumatic conditions in the United States: Part I', Arthritis \& Rheumatism 58(1), 15-25, viewed 7 December 2015, from http://www.ncbi.nlm.nih.gov/pubmed/18163481

Hiyama, Y., Yamada, M., Kitagawa, A., Tei, N. \& Okada, S., 2012, 'A four-week walking exercise programme in patients with knee osteoarthritis improves the ability of dual-task performance: A randomized controlled trial', Clinical Rehabilitation 26(5), 403-412, viewed 7 December 2015, from http://www.ncbi.nlm.nih.gov/ pubmed/21975468

Hurley, M.V., Mitchell, H.L. \& Walsh, N., 2003, 'In osteoarthritis, the psychosocial benefits of exercise are as important as physiological improvements', Exercise and Sport Sciences Reviews 31(3), 138-143, viewed 8 December 2015, from http:// www.ncbi.nlm.nih.gov/pubmed/12882480

Hurley, M.V. \& Walsh, N.E., 2009, 'Effectiveness and clinical applicability of integrated rehabilitation programs for knee osteoarthritis', Current Opinion Rheumatology 21(2), 171-176, viewed 8 December 2015, from http://www.ncbi.nlm.nih.gov/ pubmed/19339929

Hurley, M.V., Walsh, N.E., Mitchell, H., Nicholas, J. \& Patel, A., 2012, 'Long-term outcomes and costs of an integrated rehabilitation program for chronic knee pain: A pragmatic, cluster randomized, controlled trial, Arthritis Care and Research (Hoboken) 62(2), 238-247, viewed 8 December 2015, from http://www.ncbi.nlm. nih.gov/pubmed/21954131

Hurley, M.V., Walsh, N.E., Mitchell, H.L., Pimm, T.J., Pate, I.A., Williamson, E., et al., 2007 a, 'Clinical effectiveness of a rehabilitation program integrating exercise, selfmanagement, and active coping strategies for chronic knee pain: A cluster randomized trial', Arthritis Rheumatology 57(7), 1211-1219, viewed 7 Decembe 2015, from http://www.ncbi.nlm.nih.gov/pubmed/17907147

Hurley, M.V., Walsh, N.E., Mitchell, H.L., Pimm, T.J., Williamson, E., Jones, R.H., et al., $2007 \mathrm{~b}$, 'Economic evaluation of a rehabilitation program integrating exercise, selfmanagement, and active coping strategies for chronic knee pain', Arthritis Rheumatology 57(7), 120-129, viewed 7 December 2015, from http://www.ncbi. nlm.nih.gov/pubmed/17907207

Jelsma, J., Mkoka, S., Amosun, L. \& Nieuwveldt, J., 2004, 'The reliability and validity of the Xhosa version of the EQ-5D', Disability and Rehabilitation 26(2), 103-108, viewed 8 December 2015, from http://www.ncbi.nlm.nih.gov/pubmed/14668147

Jensen, C., Roos, E., Kjaersgaard-Andersen, P. \& Overgaard, S., 2013, 'The effect of education and supervised exercise vs. education alone on the time to total hip replacement in patients with severe hip osteoarthritis. A randomised clinical tria protocol', BMC Musculoskeletal Disorders 14, 21. http://dx.doi.org/10.1186/14712474-14-21

Jessep, S.A., Walsh, N.E., Ratcliffe, J. \& Hurley, M.V., 2009, 'Long-term clinical benefits and costs of an integrated rehabilitation programme compared with outpatient physiotherapy for chronic knee pain', Physiotherapy 95(2), 94-102, viewed 8 December 2015, from http://www.ncbi.nlm.nih.gov/pubmed/19627690

Kijowski, R., Blankenbaker, D., Stanton, P. \& De Smet, A., 2006, 'Arthroscopic validation of radiographic grading scales of osteoarthritis of the tibiofemoral joint', AJR American Journal of Roentenology 187(3), 794-799. http://dx.doi.org/10.2214/ AJR.05.1123

Lamb, S.E., Toye, F. \& Barker, K.L., 2008, 'Chronic disease management programme in people with severe knee osteoarthritis: Efficacy and moderators of response', Clinical Rehabilitation 22(2), 169-178, viewed 8 December 2015, from http:// www.ncbi.nlm.nih.gov/pubmed/18212037

Lidgren, L., 2003, 'The bone and joint decade 2000-2010', Bulletin of the World Health Organization Epub 81(9), 629, viewed 7 December, 2015, from http://www.ncbi. nlm.nih.gov/pmc/articles/PMC2572548/pdf/14710501.pdf

Litwic, A., Edwards, M.H., Dennison, E.M. \& Cooper, C., 2013, 'Epidemiology and burden of osteoarthritis', British Medical Bulletin 105, 185-199. http://dx.doi. org/10.1093/bmb/lds038

Lluch, E., Torres, R., Nijs, J. \& Van Oosterwijck, J., 2014, 'Evidence for central sensitization in patients with osteoarthritis pain: A systematic literature review', European Journal of Pain 18(10), 1367-1375, viewed 8 December 2015, from http://www.ncbi.nlm.nih.gov/pubmed/24700605

Lorig, K., Ritter, P.L. \& Plant, K., 2005a, 'A disease-specific self-help program compared with a generalized chronic disease self-help program for arthritis patients' Arthritis Rheumatology 53(6), 950-957, viewed 8 December 2015, from http:// www.ncbi.nlm.nih.gov/pubmed/16342084

Lorig, K.R., Hurwicz, M.L., Sobel, D., Hobbs, M. \& Ritter, P.L., 2005b, 'A national dissemination of an evidence-based self-management program: A process evaluation study', Patient Education and Counseling 59(1), 69-79, viewed 8 December, from http://www.ncbi.nlm.nih.gov/pubmed/16198220

Lorig, K.R. \& Holman, H., 2003, 'Self-management education: History, definition, outcomes, and mechanisms', Annals of Behavioural Medicine 26(1-7), viewed 8 December 2015, from http://www.ncbi.nlm.nih.gov/pubmed/12867348

Lorig, K.R., Ritter, P., Stewart, A.L., Sobel, D.S., Brown, B.W., Bandura, A., et al., 2001 , 'Chronic disease self-management program: 2-year health status and health care utilization outcomes', Medical Care 39(11), 1217-1223, viewed 8 December 2015 from http://www.ncbi.nlm.nih.gov/pubmed/11606875

Lunde, L. \& Nordhus, I.H., 2009, 'Combining acceptance and commitment therapy and cognitive behavioural therapy for the treatment of chronic pain in older adults', Clinical CaseStudies 8(4), 296-308. http://dx.doi.org/10.1177/1534650109337527

Marks, R., Allegrante, J.P. \& Lorig, K., 2005, 'A review and synthesis of research evidence for self-efficacy-enhancing interventions for reducing chronic disability: Implications for health education practice (part I)', Health Promotion Practice 6(1) 37-43, viewed 8 December 2015, from http://www.ncbi.nlm.nih.gov/ pubmed/15574526

McAlindon, T.E., Bannuru, R.R., Sullivan, M.C., Arden, N.K., Berenbaum, F., BiermaZeinstra, S.M., et al., 2014, 'OARSI guidelines for the non-surgical management of knee osteoarthritis', Osteoarthritis and Cartilage / OARSI, Osteoarthritis Research Society 22(3), 363-388. http://dx.doi.org/10.1016/j.joca.2014.01.003 
McCracken, L.M. \& Turk, D.C., 2002, 'Behavioral and cognitive-behavioral treatment for chronic pain: Outcome, predictors of outcome, and treatment process', Spine 27(22), 2564-2573, viewed 8 December 2015, from http://www.ncbi.nlm.nih. gov/pubmed/12435995

O'Mahony, R. \& Oliver, S., 2008, 'Osteoarthritis: The NICE guideline', Primary Health Care (London: Newbourne Group) 18(6), 32-37. http://dx.doi.org/10.7748/ phc2008.07.18.6.32.c6622

Ottawa Panel, 2011, 'Ottawa panel evidence-based clinical practice guidelines for patient education programmes in the management of osteoarthritis', Health Education Journal 70(3), 318-358. viewed 7 December 2015, from http://www. ncbi.nlm.nih.gov/pubmedhealth/PMH0041516/

Parker, R., Burgess, S., Dubaniewicz, A., Gouws, L., Krone, J., Madden, V., et al., 2009 'Patient satisfaction with a pilot Chronic Pain Management Programme in Cape Town, South Africa', South African Journal of Physiotherapy 65 (1), 35-40, viewed 8 December 2015, from http://www.sajp.co.za/index.php/sajp/article/view/77

Parker, R., Jelsma, J. \& Stein, D.J., 2014, 'The development of an intervention to manage pain in Amaxhosa women living with HIV/AIDS', South African Journal of Physiotherapy 70(1), 13-17.

South African Government, 2015, 'Gauteng Health on waiting list for operations: Measures to deal with long waiting times for operations announced', Home Newsroom » Media Statements, viewed 8 December 2015, from http://www.gov. za/speeches/gauteng-health-waiting-list-operations-31-mar-2015-0000

Stanford School of Medicine, c2015, Stanford Medicine, Patient Education in The Department of Medicine, viewed 8 August 2015, from http://patienteducation. stanford.edu/programs/cdsmp.html

Swendeman, D., Ingram, B.L. \& Rotheram-Borus, M.J., 2009, 'Common elements in self-management of HIV and other chronic illnesses: An integrative framework', AIDS Care 21(10), 1321-1334, viewed 8 December 2015, from http:// AIDS Care 21(10), 1321-1334, viewed 8 December 2015, from http://
web.a.ebscohost.com.ezproxy.uct.ac.za/ehost/pdfviewer/pdfviewer?vid=5\&sid= 77830ed9-9b5d-46be-9ea2-4c3488d98663\%40sessionmgr4003\&hid $=4212$
Usenbo, A., Kramer, V., Young, T. \& Musekiwa, A., 2015, 'Prevalence of Arthritis in Africa: A systematic review and meta-analysis', PLoS One 10(8), e0133858. http:// dx.doi.org/10.1371/journal.pone.0133858

Van Tulder, M., Malmivaara, A., Esmail, R. \& Koes, B., 2000, 'Exercise therapy for low back pain: A systematic review within the framework of the Cochrane collaboration back review group', Spine 25(21), 2784-2796. http://dx.doi.org/10.1097/00007632200011010-00011

Von Korff, M., Balderson, B., Saunders, K., Miglioretti, D.L., Lin, E.H.B., Berry, S., et al., 2005, 'A trial of an activating for chronic pain in primary care and physical therapy settings', Pain 113(3), 323-330. http://dx.doi.org/10.1016/j.pain. 2004.11.007

Walsh, N.E. \& Hurley, M.V., 2009, 'Evidence based guidelines and current practice for physiotherapy management of knee osteoarthritis', Musculoskeletal Care 7(1), 45-56. http://dx.doi.org/10.1002/msc.144

Western Cape Government Media Release, 2014, 'Analysis of service pressures at health facilities across the province', viewed 21 February 2014, from https://www. westerncape.gov.za/news/analysis-service-pressures-health-facilities-acrossprovince.

Woolf, A.D. \& Pfleger, B., 2003, 'Burden of major musculoskeletal conditions', Bulletin of the World Health Organization 81(9), 646-656.

World Health Organization, 2003, 'The burden of musculoskeletal conditions at the start of the new millennium', The World Health Organization Technical Repor Series, viewed 7 December 2015, from http://apps.who.int/iris/bitstream/10665/ 42721/1/WHO_TRS_919.pdf

Wu, S.V., Mu-Jung, K., Meng-Ping, W., Mei-Wun, T. \& Wan-Wen, C., 2011, 'Effects of an osteoarthritis self-management programme', Journal of Advanced Nursing 67(7), 1491-1501. http://dx.doi.org/10.1111/j.1365-2648.2010.05603.x

Zhang, Y. \& Jordan, J.M., 2010, 'Epidemiology of osteoarthritis', Clinics in Geriatric Medicine 26(3), 355-369. http://dx.doi.org/10.1016/j.cger.2010.03.001 